\title{
POLÍTICAS PÚBLICAS E POLÍTICAS ORGANIZACIONAIS PARA FORMAÇÃO DE PROFESSORES-GESTORES DO ENSINO SUPERIOR
}

\section{PUBLIC POLICIES AND ORGANIZATIONAL POLICIES FOR TRAINING ACADEMIC-MANAGER OF HIGHER EDUCATION}

Milka Alves Correia Barbosa*

Universidade Federal de Alagoas - Campus de Arapiraca - Curso de Administração

Arapiraca, AL, Brasil

E-mail: milka.correia@gmail.com

José Ricardo Costa Mendonça

Universidade Federal de Pernambuco - Programa de Pós-Graduação em Administração (PROPAD)

Recife, PE, Brasil

E-mail: jrcm@ufpe.br

Fernanda Roda de Souza Araújo Cassundé

Universidade Federal do Vale do São Francisco - Colegiado de Administração

Petrolina, PE, Brasil

E-mail: fernanda.roda@univasf.edu.br

\section{RESUMO}

Sabe-se que na maioria dos casos, os atuais gestores da educação não foram preparados para assumir o papel de gestor em instituições de ensino superior (IES). Diante disso, esperava-se que houvesse políticas públicas (PP) e políticas organizacionais (PO) voltadas ao desenvolvimento de competências gerenciais de professores de ensino superior. $O$ presente trabalho teve como objetivo analisar as políticas públicas e as políticas organizacionais de formação de professores do ensino superior para o papel de professor-gestor. O estudo adotou uma perspectiva predominantemente qualitativa. O campo empírico da pesquisa foi a Universidade Federal do Vale do São Francisco (UNIVASF) e a coleta de dados deu-se via pesquisa documental. Os dados analisados apontam uma lacuna de políticas públicas e organizacionais para formação de professoresgestores na UNIVASF. Importa reconhecer que sem políticas públicas e políticas organizacionais voltadas à formação de professores com competências gerenciais, dificilmente os dirigentes da Instituição desempenharão bem seu papel de gestor.

Palavras-chave: Políticas públicas. Políticas organizacionais. Professor-gestor. Universidade federal. Competências gerenciais.

Data de submissão: 7 de janeiro de 2016.

\section{ABSTRACT}

In most cases, the current managers of education were not prepared to assume the role of manager in the higher education institutions (HEls). Therefore, it was expected that there would be public policies (PP) and organizational policies (PO) aimed at developing managerial skills of higher education teachers. This study aimed to analyze public and organizational policies for the teachers training to the role of academic-manager. This study has adopted a predominantly qualitative perspective and data were obtained through documentary research. Data analysis showed a gap of public and organizational policies to train teachers for management from UNIVASF. Results point that without public and organizational policies related to teacher education with managerial skills, hardly the UNIVASF leaders would play well their role as academic manager.

Keywords: Public policy. Organizational policies. Academic-manager. Federal university. Managerial skills.

Data de aprovação: 12 de setembro de 2016. 


\section{INTRODUÇÃO}

O contexto do trabalho no ensino superior tem sofrido transformações significativas nas últimas décadas. Isso ocorre tanto por mudanças sociais, quanto tecnológicas que levam os diversos atores envolvidos nesse campo a empreenderem modificações estruturais e comportamentais. A própria profissão de professor nesse nível de ensino tem passado por revisões e mudanças.

No cenário brasileiro, destaque para a Lei de Diretrizes e Bases da Educação Nacional (LDB) em 1996 e as Diretrizes Curriculares Nacionais (DCN) em 2001 que trouxeram implicações diretas e indiretas para o professorado desse nível de ensino, dentre elas a apresentação de demandas às instituições de ensino em termos de composição, publicação e qualificação do corpo docente e a discussão sobre competências profissionais (PAIVA, 2007).

Com efeito, houve alterações no trabalho do professor, ampliando-se as atividades comumente associadas a esses profissionais, notadamente a docência, a pesquisa, a extensão, em virtude do aprofundamento da cultura do desempenho, que denota a supervalorização do conhecimento como uma nova forma de acumulação de capital.

A concepção do professor de ensino superior como porta-voz "soberano" de um saber dogmatizado, com habilidades para transmitir seus saberes, parece não mais corresponder ao perfil desse profissional exigido pelas instituições e pela sociedade em geral. Outras funções têm sido agregadas, tornando o exercício profissional do professor de ensino superior ainda mais complexo (MUSSELIN, 2011, 2013). São elas: o business (busca de financiamentos, negociação de projetos e convênios, assessorias, participação em diversas instâncias e entidades científicas) e as relações institucionais (que contemplam desde representar a universidade até a criação e manutenção de uma rede de relações com outras instituições).

No Brasil, o Art. $3^{\circ}$ do Decreto 94.664187 prevê a gestão universitária como uma atividade própria do professor do ensino superior, juntamente com o ensino, a pesquisa e a extensão. Assim, quando o professor atua no papel de gestor, quer seja como reitor ou pró-reitor, por exemplo, ele entra em cena o professorgestor (academic manager) - uma espécie particular de gerente, que possui funções e papéis peculiares ao mundo acadêmico, na medida em que é, antes de tudo, em geral, professor de carreira(...) (ÉSTHER; MELO, 2008), e, portanto, a multiplicidade de atividades constitui o cerne do papel de professor-gestor.

Particularizando o trabalho gerencial no contexto das instituições federais de ensino superior (IFES) brasileiras, percebe-se que cada vez mais espera-se que o professor-gestor desempenhe uma miríade de atividades administrativas além de atuar simultaneamente como educador, líder educacional, representante da instituição perante o público em geral, líder administrativo e coordenador-geral, dentre outras (SILVA, 2012).

Com efeito, a política pública implementada por meio do Programa de Reestruturação e Expansão das Universidades Federais (Reuni) provocou a ampliação da oferta de cursos nas IES, acompanhada do aumento no investimento em infraestrutura e da contratação de novos servidores (docentes e técnicos administrativos). Da confluência desses fatores, mais atenção e relevância foram direcionadas ao papel de professor-gestor, especialmente com a demanda de competências profissionais específicas para a coordenação de equipes de trabalho, melhoria da qualidade nos processos de trabalho e otimização no uso 
dos recursos públicos. Assim, acentuou-se a necessidade dos gestores de tais instituições qualificarem-se, e investirem em formação e desenvolvimento profissional (CERVIGICELE; SOUZA, 2013).

Nessa dinâmica, merece destaque o fato de que os atuais gestores da educação, na maior parte dos casos, não foram preparados para assumir tal papel em instituições de ensino superior (IES) as quais são instituições com peculiaridades e nível de complexidade únicos (KANAN; ZANELLI, 2011; MELO; LOPES; RIBEIRO, 2013). Sobre isso, Silva (2000) já apontava que uma habilidade geral adquirida por um professor em curso de doutoramento não necessariamente o prepara para o papel de dirigente de uma instituição de ensino superior.

Como modo de preencher essa lacuna era esperado que o Estado e as IES oferecessem políticas públicas (PP) e de políticas organizacionais (PO) voltadas ao desenvolvimento de competências gerenciais dos professores de ensino superior (MEYER JR., MEYER, 2011; MIRANDA, 2010; PEREIRA, SILVA, 2011).

As PP são, em geral, formuladas a partir de um fluxo top-down, por órgãos nacionais. Depois são traduzidas em leis e outros documentos, sendo implementadas nas instituições, por meio de PO. Assim, as PP afetam a forma como uma IES conduz a pesquisa, o ensino e a gestão, atingindo também os indivíduos que lá atuam. À primeira vista, pode-se dizer que este processo hierarquizado engloba níveis organizacionais distintos - micro, meso e macro. No entanto, tais segmentos imbricam-se tornando difícil ou até mesmo inadequado separá-los para fins de compreensão do fenômeno.

Tomando-se como ponto de partida esses aspectos introdutórios, o objetivo deste trabalho foi analisar as políticas públicas e as políticas organizacionais de formação de professores do ensino superior para o desempenho do papel de professor-gestor. Para tanto, na seção 2 caracteriza-se o papel de professor-gestor; na seção 3 , expõem-se algumas reflexões teóricas sobre políticas públicas e políticas organizacionais voltadas à formação desse sujeito para a gestão. Na sequência, apresentam-se os caminhos metodológicos adotados na pesquisa. Segue-se apresentando e analisando os dados coletados e, por fim, apontamentos à guisa de considerações finais.

\section{REFERENCIAL TEÓRICO}

\section{O professor-gestor}

Reconhece-se que novos desafios e pressões são colocados aos professores de ensino superior, tais como a preocupação com a massificação do ensino superior, com o declínio no status socioeconômico do ensino superior devido à sua expansão (ENDERS; MUSSELIN, 2008).

Se no passado os professores estavam envolvidos com a pesquisa, o ensino, as responsabilidades administrativas e eram responsáveis por organizar seu tempo e o peso para cada atividade, hoje, os professores estão se tornando trabalhadores acadêmicos com o aumento do controle sobre suas atividades, com a pressão por resultados que impulsionam o desenvolvimento institucional ou nacional, com a introdução de incentivos para encorajar certos tipos e comportamento e desempenho (MUSSELIN, 2013). 
Nesse contexto, atividades que antes eram consideradas secundárias ou periféricas pelo professor de ensino superior, hoje são reconhecidas por sua importância, notadamente as atividades de gestão:

Eles têm sido mais exigidos em tempo e competências que antes (em grande parte devido a delegação de novas responsabilidades de gestão para as universidades), que muitas vezes tem que ser em tempo integral ativo como gerentes, cada vez mais orientados para essas posições por causa de sua disposição ou inclinação para gestão, em vez de sua reputação científica; muitas vezes eles têm dificuldade em voltar à situação de "simples"' acadêmica (MUSELLIN, 2013, p.31).

Nesse sentido, a polarização entre trabalho acadêmico e não acadêmico vem desaparecendo e as agendas organizacionais aproximam-se em várias formas, de modo que há sobreposição entre papéis e funções desempenhados pelos professores nas universidades (WHITCHURCH, 2012), com os papéis cada vez mais se cruzando e os limites que separam a gestão da atividade acadêmica tornando-se mais tênues.

Mesmo com variação, a trajetória mais comum desses professores-gestores é iniciar atuando em suas áreas de formação para atender aos interesses de seu curso, departamento, colegiado ou centro e aos poucos ir se envolvendo em outros níveis hierárquicos até chegar à função de dirigente (MORAES, 2008). De fato, considera-se que professores-gestores desempenham papéis complexos e importantes nas universidades, dentre eles o de atender as necessidades de vários atores - incluindo estudantes, pares, sociedades, membros de colegiados; o de engajar-se no desenvolvimento da IES; o de alocar recursos limitados; o de preparar planos estratégicos e o de mediar conflitos (CARROLL; WOLVERTON, 2004).

Essa multiplicidade de papéis já estava presente no trabalho de Kerr (1982) que descreve o reitor como um personagem de muitas faces, que deve olhar em diversas direções, evitando excluir qualquer grupo importante. Aprofundando esse aspecto, a investigação de Ésther (2007) mostrou que se espera que esse sujeito seja o representante da ideologia e dos valores da IFES, e que atenda os interesses de vários grupos.

Além de reconhecer a importância desses professores-gestores para o sistema de ensino superior, os trabalhos de Melo, Lopes e Ribeiro (2013), Miranda (2010) concordam entre si sobre a necessidade de políticas públicas e de políticas organizacionais voltadas ao desenvolvimento de competências gerenciais de professores de ensino superior e que deem suporte institucional para os professores no exercício de suas atividades, facilitando a transição entre o ser professor e o ser gestor.

\section{Políticas Públicas e políticas organizacionais para a formação do professor de ensino superior para gestão}

Neste trabalho, define-se as Política Pública (PP) como aquelas de responsabilidade do Estado quanto à formulação, implementação e manutenção, estabelecidas com base num processo de tomada de decisões que envolvem organismos da sociedade política (Estado) e entidades da sociedade civil (HOFLING, 2001). Especificamente, as Políticas Públicas de Ensino Superior - que são objeto de interesse para essa discussão - definem direitos e deveres, preferências, objetivos, princípios e formas de organização do nível terciário de Educação, e "definem os territórios, as práticas e os signos acadêmicos, reconhecidos pelo Estado e pela sociedade" (MOROSINI; BITTAR, 2006, p. 166).

Já as políticas organizacionais (PO), referem-se ao conjunto de premissas, programas e ações sistemáticas no âmbito da IES que visam implementar as orientações e diretrizes das PP, possibilitando o 
desenvolvimento profissional dos sujeitos, incluindo a formação de competências profissionais dos professores (OLIVEIRA, 2006).

No que concerne às $\mathrm{PP}$, a sua influência sobre o papel dos professores-gestores é mais indireta do que direta. Assim, por exemplo, nas últimas décadas, os processos de expansão ampliaram o acesso ao Ensino Superior brasileiro a uma camada da população anteriormente excluída, alterando o cotidiano das IES, e exigindo de seus professores alterações nas competências profissionais para buscar alternativas a situações que emergiram desse novo contexto.

Importa destacar também que o processo de formação profissional, traz em si complexidade e não linearidade visto que é influenciado pelo ambiente em que se dá. Desta forma, a política organizacional pode esclarecer aos professores o que se espera deles enquanto profissionais, estimular o modo de agir comprometido com a qualificação contínua pessoal, institucional e profissional (Maciel, 2009), contribuir para a socialização, para a formação e para a experiência profissional do professor, e promove a formação de competências profissionais, dentre elas, as gerenciais.

Sobre a formação oferecida pela pós-graduação, Lourenço, Lima e Narciso (2013) chamam atenção para o fato de que tais programas ainda estão organizados e orientados para e pela pesquisa. Sendo assim, esses egressos provavelmente estarão muito mais familiarizados com as atividades de pesquisa do que com as de ensino.

O problema é que os vários papéis desempenhados pelo professor de ensino superior demandam um conjunto de competências profissionais mais amplas do que as relacionadas ao ensino e à pesquisa. Basta lembrar que o contexto de atuação desse ator ampliou-se em virtude do investimento do Governo Federal no Reuni, nos Institutos Federais de Educação, Ciência e Tecnologia, e no crescimento do número de IES privadas que trouxeram novos desafios e demandas sociais aos gestores dessas Instituições.

Sendo assim, não se pode afirmar que o título de doutor substitui políticas públicas e políticas organizacionais voltadas à formação de competências gerenciais dos professores-gestores (GUIMARÃES, 2013). As PP e PO possibilitam, por exemplo, que o dirigente universitário estude, compreenda e analise os fatores que permeiam o cotidiano da gestão do Ensino Superior em nível mundial, no Brasil e na própria instituição (CERVICELE; SOUZA, 2013).

Em virtude dos aspectos até aqui apontados, ainda se pode afirmar que a maioria dos professores que atuam gestores universitários não vem sendo formada para assumir tais funções nas instituições de ensino em que atuam e por isso grande parte deles é levada a improvisar em nesse papel (SILVA, 2012).

Pontuados esses aspectos, a seção seguinte apresenta os caminhos metodológicos adotados na presente pesquisa.

\section{PROCEDIMENTOS METODOLÓGICOS}

O presente estudo adota uma perspectiva predominantemente qualitativa, pois trabalhou com um nível de realidade que dificilmente pode ser quantificado e que procurou responder a questões muito particulares, específicas de um determinado contexto (MINAYO, 2004).

O campo empírico da pesquisa foi a Universidade Federal do Vale do São Francisco (UNIVASF), que é uma instituição federal de ensino superior (IFES) vinculada ao Ministério da Educação (MEC), com sede na 
cidade de Petrolina, nordeste brasileiro (UNIVASF, 2014). Cabe ressaltar ainda que a UNIVASF é resultado da política de expansão das universidades públicas e interiorização do ensino superior, a qual traz em seu bojo o compromisso com o desenvolvimento regional, por meio da apresentação de projetos e a realização de pesquisas que viabilizem soluções de problemas dentre as organizações regionais (UNIVASF, 2014).

Os dados foram coletados por meio de análise documental. Segundo Godoy (1995), os documentos constituem uma rica fonte de dados. Cellard (2008) divide os tipos de documentos, para análise em pesquisas sociais, em dois grupos: documentos públicos e privados. Neste estudo foram analisados documentos públicos, no âmbito da UNIVASF e fora dela, conforme se pode verificar no Quadro 1.

\section{Quadro 1-Documentos analisados}

\begin{tabular}{|c|c|}
\hline Documentos públicos & Documentos analisados na pesquisa \\
\hline $\begin{array}{l}\text { Arquivos públicos - geralmente volumosos, são } \\
\text { organizados em planos de classificação, complexos e } \\
\text { variáveis no tempo. Ainda que sejam ditos públicos, nem } \\
\text { sempre são acessíveis. Compreende arquivos } \\
\text { governamentais, assim como arquivos de natureza } \\
\text { jurídica. }\end{array}$ & $\begin{array}{l}\text { - No âmbito da UNIVASF: estatuto, relatórios de gestão, } \\
\text { organograma, comunicações oficiais (portarias, ofícios, } \\
\text { comunicações internas), Plano de Desenvolvimento } \\
\text { Institucional (PDI), Plano de capacitação da Secretaria de } \\
\text { Gestão de Pessoas (2008 a 2014) e da Pró-reitoria de } \\
\text { Ensino, Planfor, resoluções administrativas (2/2008, } \\
\text { 18/2014, Progressão funcional e acadêmicas). }\end{array}$ \\
\hline $\begin{array}{l}\text { Documentos públicos não -arquivados - são os jornais, } \\
\text { revistas, periódicos e outros tipos de documentos } \\
\text { distribuídos como boletins paroquiais, anuários } \\
\text { telefônicos, etc. }\end{array}$ & $\begin{array}{l}\text { - No âmbito da UNIVASF: site institucional, cartas de } \\
\text { serviço, vídeos institucionais. } \\
\text { - Fora na UNIVASF: site institucional do CNPq, da } \\
\text { Associação Nacional dos Dirigentes das Instituições } \\
\text { Federais de Ensino Superior (Andifes), do MEC; Plano } \\
\text { Nacional de Educação (PNE); Política Pública do Ensino } \\
\text { Superior, Política Nacional de Desenvolvimento de } \\
\text { Pessoal (PNDP) da Administração Pública Federal; Plano } \\
\text { Nacional de Pós-graduação (2011-2020); diretrizes das } \\
\text { políticas de fomento voltadas para a formação e } \\
\text { qualificação docente coordenadas pela Capes; LDB; } \\
\text { DCN; Constituição Federal, Lei 8112/90; Lei 12772/2012; } \\
\text { Lei 12.863/2013; Decreto 6.096/2006. }\end{array}$ \\
\hline
\end{tabular}

Fonte: Elaborado com base em Cellard (2008) e dados da pesquisa (2015)

Entendendo que o fenômeno em estudo envolvia uma articulação de conceitos e de níveis de análise caracterizada por uma temática ampla, pareceu adequado que algumas categorias de análise fossem definidas a priori, com base em definições constitutivas (DCs) (VIEIRA, 2004), enquanto outras emergiram a posteriori, quando da análise dos dados coletados, conforme mostra o quadro 02 : 
Quadro 2 - Categorias de Análise definidas a priori e a posteriori

\begin{tabular}{|c|c|c|}
\hline $\begin{array}{c}\text { Categorias de } \\
\text { Análise definidas a } \\
\text { priori }\end{array}$ & Definição Constitutiva (DC) & Definição Operacional (DO) \\
\hline Política Pública (PP) & $\begin{array}{l}\text { Políticas de responsabilidade do } \\
\text { Estado quanto à formulação, } \\
\text { implementação e manutenção, } \\
\text { estabelecidas com base num } \\
\text { processo de tomada de decisões } \\
\text { que envolvem organismos da } \\
\text { sociedade política (Estado) e } \\
\text { entidades da sociedade. }\end{array}$ & $\begin{array}{l}\text { - Investimento em pedagogias universitárias } \\
\text { inovadoras; } \\
\text { - Ações ou redes interinstitucionais de formação de } \\
\text { competências e desenvolvimento profissional do } \\
\text { professor; } \\
\text { - Articulação entre os conhecimentos, habilidades e } \\
\text { atitudes que constituem a especificidade das } \\
\text { atividades dos professores; } \\
\text { Inovações nos campos formativos, científicos e } \\
\text { tecnológicos das universidades }\end{array}$ \\
\hline $\begin{array}{c}\text { Política } \\
\text { Organizacional (PO) }\end{array}$ & $\begin{array}{c}\text { Conjunto de premissas, } \\
\text { programas e ações sistemáticas } \\
\text { no âmbito da IES que visam } \\
\text { implementar as orientações e } \\
\text { diretrizes das PP, possibilitando o } \\
\text { desenvolvimento profissional dos } \\
\text { sujeitos, incluindo a formação de } \\
\text { competências profissionais dos } \\
\text { professores. }\end{array}$ & $\begin{array}{l}\text { - Sentido, conteúdo e orientação - qual tipo de } \\
\text { formação, para qual finalidade, formação em quê; } \\
\text { - Modelo de professor - perfil dos professores } \\
\text { orientam a formação; } \\
\text { Destinatário - para quais professores é oferecida } \\
\text { formação; } \\
\text { - Agentes - a quem cabe a responsabilidade da } \\
\text { formação, quem serão os formadores, quais as } \\
\text { competências e legitimidade dos formadores; } \\
\text { - Organização - modelos e metodologias } \\
\text { empregados; } \\
\text { Estatuto organizacional e os sistemas de } \\
\text { reconhecimento da formação- qual o compromisso } \\
\text { organizacional com a formação; como se dará o } \\
\text { reconhecimento da formação; qual o plano de } \\
\text { formação; quem poderá participar dele; } \\
\text { Avaliação - mecanismos adotados para avaliar o } \\
\text { impacto da formação na melhora do desempenho } \\
\text { do professor em suas atividades. }\end{array}$ \\
\hline $\begin{array}{c}\text { Categoria de } \\
\text { Analise definida a } \\
\text { posteriori }\end{array}$ & Definição Constitutiva (DC) & Definição Operacional (DO) \\
\hline $\begin{array}{l}\text { Articulação entre a } \\
\text { pós-graduação e a } \\
\text { formação do professor } \\
\text { de ensino superior } \\
\text { para a gestão de IES }\end{array}$ & $\begin{array}{l}\text { Aspectos da pós-graduação que } \\
\text { direcionam a formação de } \\
\text { professores do ensino superior; }\end{array}$ & 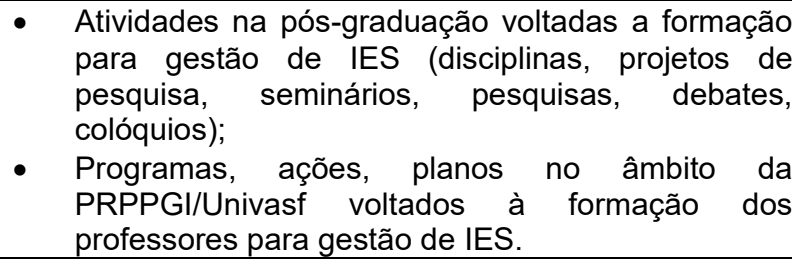 \\
\hline
\end{tabular}

Fonte: Baseado em Hofling (2001); Paiva (2007); Zabalza (2007); Isaia; Bozan; Maciel (2012) e dados da pesquisa

Em crescente utilização e legitimação nos estudos qualitativos em Administração (MOZZATTO; GRZYBOVSKI, 2011), a análise de conteúdo (AC) foi o procedimento utilizado para análise dos dados, com o apoio do software Atlas Ti.

Os dados analisados: Políticas públicas e políticas organizacionais voltadas à formação do professorgestor da UNIVASF para a gestão universitária

Sancionada em 1996 e atualizada em 2013, a Lei de Diretrizes e Bases da Educação Nacional reforça a necessidade de formação dos professores de ensino superior quando estabelece em seu artigo 52, que pelo menos um terço do corpo docente tenha titulação acadêmica de mestrado ou doutorado em conformidade com as diretrizes do MEC. 
A LDB traz novas exigências aos professores, demandando deles que busquem individualmente ou nas organizações onde trabalham, oportunidades para continuar sua formação na forma prevista dessa lei (PAIVA, 2007). No entanto, observa-se que ao estabelecer essa proporção de professores com titulação, de certa forma, a LDB alimenta a associação entre formação dos professores à pós-graduação. Nesse sentido, importante distinção entre formação e preparação é feita por Lourenço, Lima e Narciso (2013). Enquanto a formação assume caráter processual, a preparação refere-se a algo mais específico, pontual, localizado.

Note-se ainda que o texto da LDB não faz referência à forma como se dará o processo de formação contínua dos professores de ensino superior, em quais instâncias ele acontecerá, quais as tecnologias de aprendizagem e de pedagogia serão adotadas, bem como e quais redes institucionais serão formadas para tal.

Tal como Dias e Lopes (2003) afirmam, percebe-se que nos documentos produzidos sobre formação docente, após a promulgação da Lei de Diretrizes e Bases da Educação Nacional de 1996, o conceito de competências tem sido elemento fundamental na redefinição do processo de formação contínua dos professores em torno de sua profissionalização, pautada na concepção de competência profissional. Dentre eles estão as Diretrizes Curriculares Nacionais (DCN), em cujo texto é possível encontrar elementos que explicitam o direcionamento das políticas públicas para a formação de competências dos professores.

Da leitura das DCN é ainda possível identificar a ênfase na formação com foco no "atendimento das demandas de um exercício profissional específico que não seja uma formação genérica e nem apenas acadêmica" (BRASIL, 2001, p. 28). Ou seja, indiretamente, essa normativa amplia as arenas nas quais a formação pode se dar, para além da pós-graduação, por exemplo. Por outro lado, em seu Art. 1, a DCN delega à IES a tarefa de planejar a estrutura institucional e curricular para formação de professores, semelhante ao que foi encontrado na LDB.

Desta forma, apesar de se concordar com Murari e Helal (2009) que as DCN juntamente com a LDB foram marcos de renovação do ensino superior, pois difundiram o conceito de competências atrelado ao de formação, observa-se que nenhuma dessas normativas chega a contemplar claramente a operacionalização da formação de professores do ensino superior especificamente para a gestão de IES.

No âmbito dos programas voltados para a formação e qualificação docente coordenados pela Coordenação de Aperfeiçoamento de Pessoal de Nível Superior (CAPES) e pelo CNPq, o Mestrado Interinstitucional (Minter), o Doutorado Interinstitucional (Dinter), o Programa Nacional de Cooperação Acadêmica (Procad), o Programa de Formação Doutoral Docente (Prodoutoral) parecem estar alinhados à necessidade de formação de professores, mas não contemplam todas as competências necessárias ao professor de ensino superior, limitando sua ênfase à competência científica e à técnico-profissional. Nas diretrizes norteadoras desses programas, é possível ainda encontrar sinais da concepção de formação como sinônimo de especialização dentro de uma área específica do saber, com pouca ou nenhuma preocupação com a preparação dos professores para atividade de gestão universitária.

Quanto às políticas que versam sobre a carreira de magistério superior, verificou-se que a Lei 12772/2012, a qual dispõe sobre a estruturação do Plano de Carreiras e Cargos de Magistério Federal, em seu Artigo $2^{\circ}$ explicita que: "são atividades das Carreiras e Cargos Isolados do Plano de Carreiras e Cargos de Magistério Federal aquelas relacionadas ao ensino, pesquisa e extensão e as inerentes ao exercício de 
direção, assessoramento, chefia, coordenação e assistência na própria instituição, além daquelas previstas em legislação específica" (BRASIL, 2012, p. 2).

Ainda tratando dessa legislação, não há referência à necessidade de competências profissionais para o ingresso na carreira - somente a titulação de doutor, tampouco elas são tomadas como critérios de promoção. No que se refere à formação de professores do ensino superior, o conteúdo da Lei 12722/2012 praticamente não aborda as dimensões analisadas nesta pesquisa, deixando de se referir a, por exemplo, necessidade de articulação entre os conhecimentos, habilidades e atitudes que constituem a especificidade das atividades dos professores, ações ou programas na esfera do Governo Federal que ofereçam investimento em pedagogias universitárias inovadoras, tampouco ações de formação de competências e desenvolvimento profissional do professor. Sendo assim, percebeu-se que na Lei 12722/2012, a referência à formação do professor limita-se a reconhecer a necessidade de qualificação contínua, com vistas à melhoria do desempenho do docente, especificamente em tarefas de pesquisa e ensino.

De fato, em comum, percebe-se que as Leis 12722/2012, 8112/90 e 7596/87 trazem dispositivos que estimulam a busca individual pela formação de competências, como a licença para capacitação.

Ao se analisar a estrutura remuneratória do Plano de Carreiras e Cargos de Magistério Federal (BRASIL, 2013), verificou-se, por exemplo, que a Retribuição por Titulação (RT) exclui outras experiências e formações do professor que não sejam advindas da titulação na pós-graduação stricto sensu. É precisamente sobre isso que Bergue (2014) chama atenção: a dificuldade de compatibilizar a lógica de competências com os demais princípios da administração pública.

Mostrou-se oportuno analisar o Decreto-Lei 5.707/06, que institui a Política Nacional de Desenvolvimento de Pessoal (PNDP) da Administração Pública Federal (BRASIL, 2006), considerando-se que ele afeta mais diretamente os professores que atuam em IFES, como a UNIVASF. Nesse documento, o desenvolvimento de competências individuais está atrelado à melhoria de processos gerenciais e desempenho das instituições públicas federais de ensino superior e há diretrizes que fazem referência ao imperativo de promover a capacitação gerencial do servidor e sua qualificação para o exercício de atividades de direção e assessoramento. Considerando-se que o professor de uma IFES é também um servidor, então se toma essa diretiva como evidência da necessidade de prepará-lo para o papel de gestor.

Como desdobramento do Decreto-Lei 5.707/06, está previsto que os órgãos setoriais passam a ter a responsabilidade de desenvolver planos de qualificação para seus servidores baseados em competências, buscando modernizar os métodos de aprendizagem e o desenvolvimento de pessoal. Assim, as IFES devem desenvolver políticas e programas organizacionais de formação, sistematicamente planejados e implementados de maneira contínua, visando desenvolver competências que preparem os sujeitos da melhor forma possível, dentro de dadas circunstâncias, para os diversos papéis (atuais e possíveis) dentro do contexto organizacional, o que inclui os professores que podem ser preparados para ocupar posições administrativas. Aqui se percebe mais um possível ponto de imbricamento entre políticas públicas e políticas organizacionais.

Apesar disso, chama-se a atenção para o fato de que, se por um lado o Decreto 5.707/2006 apoia o desenvolvimento de competências individuais dos servidores públicos federais, por outro, a Lei 12722/2012, ao tratar da carreira do professor de magistério federal, ainda se baseia no cumprimento de critérios 
burocráticos que deixam de fora a valorização de saberes e experiências não relacionadas aos papéis de docente, de extensionista e de pesquisador.

Ainda em consonância com as diretrizes definidas pela PNDP, ressaltam-se iniciativas, como por exemplo, o estabelecimento de uma rede nacional de escolas de governo, liderada pela Escola Nacional de Administração Pública (Enap) e o Programa Nacional de Formação em Administração Pública (Pnap). Tanto as escolas de governo quanto o Pnap buscam contribuir para minimizar dois grandes desafios - a qualificação do quadro funcional atuante na gestão do Estado brasileiro e a qualificação dos professores que atuam nas escolas de educação básica.

Em comum, essas iniciativas desenvolvem ações voltadas à formação de sujeitos com base nos referenciais de competência (ENAP, 2009), porém, não se pode afirmar que se trata de iniciativas diretamente voltadas ao professor-gestor, sujeito que atua em uma instituição, como uma universidade federal, cujas peculiaridades demandam a formação de competências que o permita atuar neste contexto específico.

No âmbito da pós-graduação, analisando-se o Plano Nacional de Pós-Graduação (PNPG) de 20112020, verifica-se que os programas estão organizados e orientados para e pela pesquisa. Estão previstos o aumento do número de programas, novas parcerias da CAPES com fundações de pesquisa, a necessidade de formar professores, mas todas essas demandas novamente centram-se na formação para a pesquisa; para preparar profissionais que mesmo atuando fora da academia, sejam formados a partir da lógica da pósgraduação.

Percebeu-se ainda que as diretrizes encontradas no PNPG parecem reforçar o não reconhecimento da importância de alguns papéis desempenhados pelos professores de ensino superior - como o de gestor, por exemplo, posto que ao priorizarem as atividades de pesquisa na formação, os programas de pósgraduação continuam fortalecendo, mesmo que não intencionalmente, [...] "a crença de que para ser professor basta conhecer a fundo determinado conteúdo ou, no caso específico do ensino superior, ser um bom pesquisador" (PACHANE; PEREIRA, 2004, p. 5).

Cunha (2003) já alertava para o modo como a formação do professor universitário é tratada: restrita aos saberes do conteúdo de ensino. Ou seja, o professor deve ser um especialista em uma área específica, a partir de conhecimento apropriado via pós-graduação stricto sensu, e do conhecimento legitimado academicamente, junto a seus pares, em um determinado campo científico.

Dando suporte institucional a esse padrão, as análises dos sites da Capes e do CNPq mostraram que os mecanismos de avaliação das universidades brasileiras têm aporte em duas vertentes principais (CUNHA, 2003): o componente da investigação e o componente da docência, nesta ordem de importância, ao que parece. Na primeira vertente, há concepção de professor como produtor de conhecimento, na segunda, cabe ao professor a tarefa da educação escolarizada. Sendo que a primeira vertente - a da investigação - "assume maior prestígio, especialmente no espaço da pós-graduação, adentrando, pouco a pouco a graduação" (CUNHA, 2003, p. 53).

Alinhados a essas duas vertentes nos documentos da Pró-reitoria de Pesquisa, Pós-graduação e Inovação (PRPPGI) da UNIVASF, bem como nos relatórios de gestão da Instituição (2012 a 2014), não foi encontrada menção a indicadores qualitativos ou quantitativos para acompanhar a performance dos professores em papéis de gestão e sua contribuição ao desempenho da IFES. Esse achado não é inesperado 
quando se entende que as PP trazem desdobramentos para os projetos pedagógicos dos programas de pósgraduação (PPG), repercutindo também na formação de professores.

Diante dos aspectos aqui apresentados, acredita-se que o investimento em formação de professores com competências para atuarem na gestão pode estar sendo deixado de lado, por se tratar de atividade que formalmente pouco agrega à avaliação dos programas de pós-graduação, aos cursos de graduação e à carreira desses indivíduos. Nesse sentido, acredita-se que, enquanto as políticas públicas de pós-graduação mantiverem o foco na valorização de competências de pesquisa e docência, a formação de professores para atuar na gestão de IES enfrentará dificuldades para prosperar e se institucionalizar nos PPGs.

Tendo como base as análises do Plano Nacional de Educação (PNE) (2014-2014) (BRASIL, 2014), Plano Nacional de Pós-graduação (2011-2020) (BRASIL, 2010), as diretrizes das políticas de fomento voltadas para a formação e qualificação docente coordenadas pela Capes, LDB, DCN, Lei 8112/90, Lei 12772/2012, Lei 12.863/2013 e Decreto 6.096/2006, verificou-se que os dados analisados mostraram que as atuais PP ainda estão em estágio incipiente e não apresentam determinadas dimensões esperadas como ações ou redes interinstitucionais de formação, articulação entre pós-graduação e formação para gestão, inovações nos campos formativos, articulação entre formação do professor, melhoria da qualidade e desenvolvimento da educação, articulações entre os conhecimentos, habilidades e atitudes que constituem as atividades dos professores.

No que tange à categoria analítica política organizacional, em sendo a UNIVASF uma instituição pública federal de ensino superior, tanto a LDB como as DCN são fortes direcionadoras das ações organizacionais como um todo, inclusive daquelas ligadas especificamente à formação de seus professores.

Neste sentido, analisou-se o Plano de Desenvolvimento Institucional (PDI) da UNIVASF do período de 2009-2014, no qual se percebeu que a preocupação principal é com a qualificação dos professores por meio de mestrados, doutorados e pós-doutorados, com vistas a buscar a melhoria da qualidade do ensino, da extensão e da pesquisa. Nesse documento, ainda que se encontrem trechos com referência à importância da gestão para o alcance dos objetivos organizacionais, não há indícios da preocupação com a preparação de professores para as atividades de gestão em quaisquer níveis organizacionais.

Sobre esse aspecto, segundo Zabalza (2007), a responsabilidade pela formação deve ser compartilhada entre a IES e o professor, e, portanto, as universidades devem encontrar saídas para a formação de sua força de trabalho, o que com certeza demanda a alteração de suas políticas organizacionais de administração de pessoal.

No contexto da UNIVASF verificou-se que o problema já se apresenta no planejamento de tais políticas, na medida em que o PDI da instituição não traz diretrizes a esse respeito, comprometendo, assim, a elaboração e operacionalização de possíveis programas voltados à preparação de professores para atuarem na gestão da IFES. Cabe ainda revelar que o regimento geral único da UNIVASF se encontra em fase de elaboração por uma comissão.

Observando o desdobramento da política pública de pós-graduação na UNIVASF, percebe-se que no Plano de Formação Institucional (Planfor) de 2009-2013 e no de 2014-2017 há clara associação entre formação de professores, pesquisa e pós-graduação, inclusive com a meta de aumentar em $20 \%$ o quantitativo de doutores da instituição. Nesses planos, a formação do quadro de professores (e 
pesquisadores) é tida como condição para que a Instituição possa potencializar sua intervenção no contexto local, regional e nacional, mas não há menção alguma à preparação do professor para a gestão da IFES.

Corroborando esse aspecto, os programas interinstitucionais de Minter e Dinter já implementados e/ou em fase de elaboração até o final do levantamento de dados para este estudo, voltam-se prioritariamente à ampliação das áreas estratégicas de pesquisa e grupos de pesquisa, sem referência à preparação dos professores para a gestão de IFES. Aqui cabe recordar que a Lei de Diretrizes Básicas (BRASIL, 1996) não determina e nem limita que a formação dos professores da educação superior se dê exclusivamente nos cursos de mestrado e doutorado.

Especificamente no tocante à política organizacional de gestão de pessoas, as versões do Plano de Capacitação (PCA) elaborado pela Secretaria de Gestão de Pessoas (SGP) da UNIVASF no período de 2008 a 2014 baseiam-se no Decreto 5.825/2006, Decreto 5.824/2006, Decreto 5.707/2006, Lei 12722/2012, Resolução Conuni 02/2008, evidenciando o claro imbricamento entre políticas públicas e políticas organizacionais.

No PCA de 2008, 2009, 2010 e de 2011 foi encontrada uma diretriz que direciona o plano também para capacitar o servidor para atuar na gestão pública, sem, no entanto, designar uma linha de formação ou programas voltados a professores que desempenham papel de gestor, quer seja nível estratégico ou intermediário. Em 2012, iniciou-se um curso de desenvolvimento de gestores públicos voltado aos dirigentes da UNIVASF que não chegou a ser concluído em virtude da evasão dos participantes. Esse fato aponta uma via fértil de pesquisa, no sentido de questionar o pressuposto de que se a IFES oferecer oportunidades para formação de competências, os professores participarão.

Observou-se que os PCA dos anos de 2013 e 2014 contêm o Programa de Formação Gerencial, cujo público-alvo é composto pelos dirigentes da Instituição, sejam eles professores ou não. Note-se que, em 2013, neste programa estavam incluídas rodas de conversas - sobre temas diversos acerca da gestão pública em geral; curso sobre competências gerenciais - com o foco em gestão universitária; curso de gestão estratégica - direcionado à gestão de IES, prevendo a adoção de metodologias inovadoras. Já em 2014, manteve-se a oferta de 2013 e houve a inclusão de um curso de formação para coordenadores e vice-coordenadores e um curso de liderança para gestores, aumentando, assim, as oportunidades de formação para professoresgestores.

Apesar disso, a existência de planos de capacitação não foi suficiente para caracterizar a UNIVASF, até o final desta pesquisa, como espaço de formação de competências gerenciais para seus gestores, conforme aconselham autores como Fleck e Pereira (2011) e Zabalza (2012). Atente-se que esse aspecto merece atenção dos formuladores das PO para averiguar possíveis problemas na concepção dessas ações de formação.

Da análise dos documentos que versam (ou deveriam versar) sobre políticas pública, percebe-se que já nos textos não há definição de programas, ações, diretrizes que possam se caracterizar como apoio formal e direcionado à formação de professores para a gestão de IES. Da mesma forma aconteceu com os documentos que se relacionam às políticas organizacionais; cenário que, de certa forma já era esperado, tendo em vista que políticas organizacionais podem ser tomadas como desdobramentos de políticas públicas, principalmente no contexto das IFES. Portanto, seja no nível macro ou no meso, seja em termos de políticas 
públicas e políticas organizacionais, a análise documental não evidenciou que há suporte institucionalizado para formar os atuais e futuros professores-gestores da UNIVASF.

\section{APONTAMENTOS FINAIS}

O presente trabalho teve como objetivo analisar as políticas públicas e as políticas organizacionais de formação para o desempenho do papel de professor-gestor. Nesse sentido, pode-se afirmar que, não obstante tenham sido encontrados pontos de imbricamento entre PP e PO que caracterizam a interação entre esses dois níveis de política, no âmbito da UNIVASF, não se encontraram políticas públicas e organizacionais formalmente institucionalizadas voltadas à formação dos professores para a gestão universitária.

Os dados da análise documental corroboraram a lacuna de políticas públicas e organizacionais voltadas à preparação de professores-gestores da UNIVASF, apontada por autores do referencial teórico (ÉSTHER, 2007; MEYER; MEYER JR. 2011; SILVA, 2000; SILVA, 2011, 2012). Nos documentos que tratam sobre políticas públicas de ensino superior percebe-se a ausência de programas, ações, diretrizes que possam se caracterizar como apoio institucional e direcionado à formação de professores para a gestão de IES. De modo semelhante, a análise das políticas de pós-graduação mostrou que não cabe mais tomá-la como único espaço voltado à formação, posto que as atividades dos professores do ensino superior mostramse cada vez mais inter-relacionadas, e demandam desse indivíduo muito mais do que a expertise em pesquisa.

Como também, no âmbito da UNIVASF, há um hiato de PO que ofereçam suporte ou preparação para os professores que atuam no papel de gestor universitário, indicando que o desenvolvimento de competências profissionais de gestão dos professores da Univasf está pautado basicamente em esforços individualizantes (PAIVA; 2007) e informais (SALES; VILLARDI, 2014).

Ampliando-se o espectro de análise, sabe-se que a expansão e da massificação do ensino superior mudaram a relação das IES com o Estado e vieram acompanhadas de heterogeneidade de professores e estudantes, e do questionamento sobre a concepção humboldtiana de universidade (AMARAL, 2008). Desse ponto de vista, a lacuna de políticas públicas e políticas organizacionais pode sinalizar a maneira como o sistema de ensino superior brasileiro e suas instituições (ainda não) reagem a essas tendências.

Nessa perspectiva, apesar de as pressões por eficácia, eficiência terem aumentado sobre as instituições federais de ensino superior, não significa que tais organizações necessariamente contêm como aporte políticas públicas e políticas organizacionais (a exemplo da UNIVASF) para a formação e preparação de seus gestores. Há um desencontro entre a formação recebida e as responsabilidades dos professores; isso é preocupante, tendo em vista que no atual contexto do ensino superior do Brasil, com a expansão e a interiorização das IFES, os professores-gestores assumem o protagonismo na implementação da Política Pública para Educação Superior.

Esse hiato é preocupante quando se constata que o professor, ao não contar com políticas institucionais para prover sua formação, provavelmente irá buscá-la por si só e, ao fazer isso, pode deixar de alinhar suas necessidades individuais às necessidades da IES (ZABALZA, 2007). Ao buscar meios próprios de apropriar-se de competências gerenciais, quer seja por auto direcionamento ou aprendendo no cotidiano (PAIVA, 2007), muitos professores se baseiam em exemplos de seus "mestres respeitados" para desenvolver suas próprias competências. Essa tendência fortalece o que Zabalza (2007) chama de "visão não profissional 
da docência" - aquela em que se acredita que uma profissão não precisa de preparação; basta a vivência, a experiência e a vocação.

Os dados sobre a lacuna de PP e PO podem também ser tomados como subsídios pela UNIVASF para planejar momentos de preparação para professores que assumem cargos de direção. Em especial, sugere-se aos formuladores de políticas organizacionais o engajamento em iniciativas para apreender mais sobre as feições emergentes do trabalho acadêmico, de forma a poder identificar os efeitos das políticas públicas nos professores e nos diferentes papéis que eles desempenham na IFES, avaliando problemas que podem ser resolvidos com mudanças nas políticas em âmbito da instituição.

Longe de esgotar as discussões, é possível traçar algumas possibilidades de pesquisas futuras: nesta investigação, partiu-se do pressuposto de que se a IES oferecer oportunidades para formação de competências, os professores participarão. Entretanto, em instituições com políticas organizacionais de formação institucionalizadas, os professores, de fato, se fizeram presentes? Ou houve evasão nos cursos de formação gerencial? Qual a percepção desses sujeitos acerca da formação? Como também, no presente estudo, recorreu-se a análise documental para coleta de dados, mas entende-se ser igualmente frutífero ouvir atores institucionais, tais como os planejadores de políticas públicas e organizacionais em instância como o MEC, CNPq, Andifes, Capes acerca da temática;

Por fim, reforça-se que esta investigação se pautou no entendimento de que complexidade e a dinâmica da realidade educacional brasileira vêm demandando cada vez mais o alcance de níveis de excelência em ensino, pesquisa e extensão nas IFES, e nesse cenário a formação do professor de ensino superior para a gestão universitária é uma questão central.

\section{REFERÊNCIAS}

AMARAL, A. Transforming higher education. In: AMARAL, A.; BLEIKLIE, I.; MUSSELIN, C. From Governance to Identity. London: Springer, 2008. p. 81-94.

BERGUE, S. T. Gestão de estratégica de pessoas no setor público. São Paulo: Atlas, 2014.

BRASIL. Lei 12.863 de 24 de setembro de 2013. Altera a Lei no 12.772, de 28 de dezembro de 2012, que dispõe sobre a estruturação do Plano de Carreiras e Cargos de Magistério Federal. Brasília, DF: Presidência da República, 2013.

BRASIL. Lei 12.772 de 28 de dezembro de 2012. Dispõe sobre a estruturação do Plano de Carreiras e Cargos de Magistério Federal. Brasília: Presidência da República, 2012.

BRASIL. Plano Nacional de Pós-Graduação - PNPG 2011-2020. Brasília, DF: CAPES, 2010.

BRASIL. Decreto $n^{\circ}$ 5.707, de 23 de fevereiro de 2006. Institui a Política e as Diretrizes para o Desenvolvimento de Pessoal da administração pública federal direta, autárquica e fundacional, e regulamenta dispositivos da Lei $n^{\circ} 8.112$, de 11 de dezembro de 1990. Brasília, DF: 2006.

BRASIL. Diretrizes curriculares nacionais para a formação de professores da educação básica, em nível superior, curso de licenciatura, de graduação plena. Brasília, DF: MEC/CNE, 2001.

BRASIL. Lei $\mathbf{n}^{\circ} \mathbf{9 . 3 9 4}$ de 20 de dezembro de 1996. Estabelece as diretrizes e bases da educação nacional, 8. ed. Brasília: Câmara dos Deputados, Edições Câmara, 1996.

BRASIL. Lei 9.112 de 11 de dezembro de 1990. Dispõe sobre o regime jurídico dos servidores públicos civis da União, das autarquias e das fundações públicas federais. Brasília, DF: 1990.

COORDENAÇÃO DE APERFEIÇOAMENTO DE PESSOAL DE NÍVEL SUPERIOR (CAPES). Portaria $\mathbf{n}^{\circ} \mathbf{1 4 0 ,}$ de $\mathbf{0 2}$ de outubro de 2013. Novo regulamento do Programa de Formação Doutoral Docente, Prodoutoral. Brasília, DF: CAPES, 2013.

CARROLL, J. B.; WOLVERTON, M. Who becomes a chair? In: GMELCH, W.; SCHUH, J. H. (Eds.). The life cycle of a department chair, n. 126, p. 3-10, 2004.

CELLARD, A. A análise documental. In: POUPART, J. et al. A pesquisa qualitativa: enfoques epistemológicos e metodológicos. Petrópolis: Vozes, 2008. p. 295-316. 
CERVIGICELE, G.M.; SOUZA, R. Gestão democrática e formação de gestores no ensino superior: quais as necessidades para a o exercício na coordenação de colegiado de curso? In: XIII Coloquio de Gestión Universitária em Américas. Anais... Buenos Aires: INPEAU, 2013.

CUNHA, M. I. Políticas públicas e docência na universidade: novas configurações e possíveis alternativas. Revista Portuguesa de Educação. v.16, n.2, p.45-68, 2003.

DIAS, R. E.; LOPES, A. C. Competências na formação de professores no brasil: o que (não) há de novo. Educação e Sociedade, Campinas, v. 24, n. 85, p. 1155-1177, 2003.

ESCOLA NACIONAL DE ADMINISTRAÇÃO PÚBLICA. Escolas de governo e gestão por competência: mesa-redonda de pesquisa-ação. Brasília: ENAP, 2009.

ENDERS, J.; MUSSELIN, C. "Back to the Future? The Academic Professions in the 21st Century". In: Higher education to 2030. OECD Publishing, 2008. v. 1, p. 125-250.

ÉSTHER, A. B. A construção da identidade gerencial dos gestores da alta administração das universidades federais em Minas Gerais. 2007. 276 f. Tese (Doutorado em Administração) - Universidade Federal de Minas Gerais, Belo Horizonte, 2007.

ÉSTHER, A. B.; MELO, M. C. O. L. A construção da identidade gerencial dos gestores da alta administração de universidades federais em Minas Gerais. Cadernos EBAPE.BR, v. 6, n.1, p. 01-17, 2008.

FLECK, C. F.; PEREIRA, B. A. D. Professores e Gestores: Análise do perfil das competências gerenciais dos coordenadores de pós-graduação das instituições federais de ensino superior (IFES) do RS, BRASIL. Organizações \& Sociedade, v.18, n.57, p. 285-301, 2011.

GODOY, A. S. Pesquisa qualitativa: tipos fundamentais. Revista de Administração de Empresas, v.35, n.3, p.20-29, 1995.

GUIMARÃES, J. C. Gestão em IFES: as razões que determinam o doutor como gestor - Uma abordagem sob a perspectiva das competências individuais. Revista Eletrônica do Mestrado Profissional em Administração da Universidade Potiguar, v. 5, n. 2, p. 35-47, 2013.

HOFLING, E. M. Estado e políticas (públicas) sociais. Cadernos CEDES [online]. 2001, v. 21, n. 55, p. 30-41, 2001.

ISAIA, S; BOLZAN, D.P.V.; MACIEL, A. Qualidade da educação superior: a Universidade como lugar de formação. Porto Alegre: EDIPUCRS, 2012.

KANAN, L. A.; ZANELLI, J. C. Características do trabalho de coordenadores de curso no contexto universitário. REP Revista Espaço Pedagógico, v. 18, n. 1, p. 151-170, 2011.

KERR, C. Os usos da universidade. Fortaleza: Edições UFC, 1982.

LOURENÇO, C.D.S.; LIMA, M.C.; NARCISO, E. R.P. Formação Pedagógica no Ensino Superior: o que diz a Legislação e a literatura em Educação e Administração? In: IV Encontro de Ensino e Pesquisa em Administração e Contabilidade. Anais... Brasília. ANPAD, 2013.

MACIEL, A. M. R. O processo formativo do professor no ensino superior: em busca de uma ambiência (trans)formativa. In: ISAIA, S.M.A.; BOLZAN, D. P. V. MACIEL, A. M. R. (Org.). Pedagogia universitária: tecendo redes sobre a Educação Superior. Volume 1. Santa Maria: Editora UFSM, 2009, p. 63-77.

MELO, M. C. O. L; LOPES, A. L. M.; RIBEIRO, J. M. O cotidiano de gestores entre as estruturas acadêmica e administrativa de uma instituição de ensino superior federal de Minas Gerais. Revista Organizações em Contexto, v. 9, n. 17 , p. 205-227, 2013.

MEYER Jr., V.; MEYER, B. Managerialism na Gestão Universitária: Dilema dos Gestores de Instituições Privadas. In: Encontro Nacional dos Programas de Pós-Graduação em Administração, 35.,2011, Rio de Janeiro. Anais..., Rio de Janeiro: ANPAD, 2011.

MINAYO, M. C. de S. O desafio do conhecimento: pesquisa qualitativa em Saúde. 8. ed. São Paulo: Hucitec, 2004.

MIRANDA, A. R. A. Um estudo sobre a dinâmica identitária de professoras gerentes de uma universidade pública. 2010. 162 f. Dissertação (Mestrado em Administração) - Universidade Federal de Lavras. Lavras, Minas Gerais, 2010.

MORAES, L. V. dos S. de. A trajetória de mulheres que se tornaram reitoras em instituições de ensino superior no Estado de Santa Catarina. 2008. 240 f. Tese (Doutorado em Engenharia de Produção) - Centro Tecnológico, Universidade Federal de Santa Catarina, Florianópolis, 2008.

MOROSINI, M. C.; BITTAR, M. Verbete Política Pública. In: FRANCO, M. E. D. P.; BITTAR, M. (Org.) Enciclopédia de pedagogia universitária, Porto Alegre: RIES/ INEP, 2006.

MURARI; J. M. F; HELAL, D. H. O estágio e a formação de competências profissionais em estudantes de Administração. Revista Gestão e Planejamento Salvador, v.10, n. 2, p. 262-280, 2009.

MUSSELIN, C. Redefinition of the relationships between academics and their university. High Education, n. 65, p.25-37, 2013. 
MUSSELIN, C. European universities' evolving relationships: the state, the universities, the professoriate. CHER Conference, Reykjavik, 2011.

OLIVEIRA, D. P. R. Estrutura organizacional: uma abordagem para resultados e competitividade. São Paulo: Atlas, 2006.

PAIVA, K. C. M. Gestão de competências e a profissão docente um estudo de caso em universidades no Estado de Minas Gerais. 2007. 278f. Tese (Doutorado em Administração), Universidade Federal de Minas Gerais, Belo Horizonte, Brasil, 2007.

PACHANE, G. G.; PEREIRA, E. M. A. A importância da formação didático-pedagógica e a construção de um novo perfil para docentes universitários. Revista Iberoamericana de Educación, n. 33, v. 1, 1-13, 2004.

PEREIRA, A.L.C.; SILVA, A. B. As Competências Gerenciais em Instituições Federais de Educação Superior. Cadernos EBAPE, v. 9, p. 627-647, 2011.

SALLES, M. A. S. D.; VILLARDI, B. Q. O Desenvolvimento de Competências Gerenciais na Prática dos Gestores no Contexto de uma IFES Centenária. In: EnAPG, 6, 2014, Belo Horizonte, Anais... Belo Horizonte: ANPAD, 2014.

SILVA, F. M. V. A transição para a gestão universitária: o significado das relações interpessoais. R. Adm. FACES, v. 11, n. 4, p. 72-91, 2012.

SILVA, F. M. V. A transição de líder para contribuidor individual. 2011. 273f. Tese (Doutorado em Engenharia da Produção) - Universidade Federal de Santa Catarina, Florianópolis, 2011.

SILVA, M. A. A aprendizagem de professores da Universidade Federal de Santa Catarina para dirigir as unidades universitárias. 2000. 268f. Tese (Doutorado em Engenharia da Produção) - Universidade Federal de Santa Catarina, Florianópolis, 2000.

UNIVERSIDADE FEDERAL DO VALE DO SÃO FRANCISCO (UNIVASF). Relatório de Gestão 2014. Petrolina, $2014 \mathrm{c}$. Disponível em

http://www.univasf.edu.br/acessoainformacao/arquivos/RelatorioGestao_UNIVASF_2014.pdf>. Acesso em: 10/01/2015.

WHITCHURCH, C. Reconstructing identities in higher education: London: Routledge, 2012.

ZABALZA, M. Formación del Professorado para la Enseñanza Superior: la busqueda de la calidad. ISAIA, S. M. A; BOLZAN, D. P. V.; MACIEL, A. M. R. (ORGS.). Qualidade da educação superior: a Universidade como lugar de formação. Porto Alegre: EDIPUCRS, v.2, p. 151-174, 2012.

ZABALZA, M. O ensino universitário. Porto Alegre: Artmed, 2007. 